\title{
SELF EFFICACY TO REFRAIN FROM DRUG ADDICTION RELAPSE AMONG POST DRUG REHABILITATION RESIDENTS IN TANAH MERAH, SAMARINDA, EAST KALIMANTAN
}

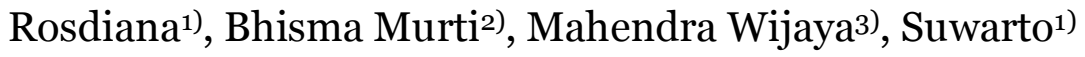 \\ 1) Doctoral Program in Development Promotion, \\ Sebelas Maret University \\ 2) Masters Program in Public Health, Sebelas Maret University \\ 3) Faculty of Social Sciences and Politics, Sebelas Maret University
}

\begin{abstract}
BACKGROUND: Drug abuse and illicit drug trafficking continue to be a serious threat to many countries, including Indonesia. Drug trafficking such as shabu (methamphetamine) continued to increase in Indonesia from 2008 to 2011. Post drug addiction rehabilitation may need to work with families of post drug users in order to prevent drug use relapse. This study aimed to examine the effect of family support on post drug user's self-efficacy to refrain from drugs addiction relapse.

SUBJECT AND METHODS: This was a qualitative study with case study design, conducted in Tanah Merah Rehabilitation Center, Samarinda, East Kalimantan, Indonesia. A sample of key informants including post drug users, family members, and health personnel at the post drug rehabilitation institution, was used to collect data. The dependent variable was self-efficacy. The independent variable was family support. The data was collected by in-depth interview, focus group discussion, and direct observation.

RESULTS: Family consisting of parent, wife, children, brother, sister, or the loved one, could prevent former drug users from relapse. The indicators of family support that were important to prevent relapse included motivation from the family members, emotional support (such as attention and affection), a sense of caring, information support in the forms of suggestion, and confidence to recover from the family members.

CONCLUSION: Family support has positive impact on self-efficacy among post drug users to refrain from drug addiction relapse. Drug addiction rehabilitation institution should work together with families of the post drug users, in order to prevent drug addiction relapse.
\end{abstract}

Keywords: self-efficacy, drug addiction, family support, relapse 